\title{
Incidence of CrossFit Related Injuries: A Metaalysis
}

José Carlos Figueiredo Fernandes, ${ }^{1 *}$ Laura Manhaes Ressiguier Penna de Moraes, ${ }^{2}$ Lucas Giovanni Cattaneo, ${ }^{2}$ Wallison Fernandes Gomes, ${ }^{2}$ Ricardo Galotti, ${ }^{2}$ Rafael Abucater Lorenzoni, ${ }^{3}$ Luiz Carlos Palhares Brum, ${ }^{3}$ Jhonne Pereira De Jesus, ${ }^{3}$ Osmar Gomes Carvalho Junior, ${ }^{3}$ Leonardo Abucater Lorenzoni, ${ }^{4}$ Helcio Lorenzoni Filho, ${ }^{4}$ Gioavana Brasil Santos $^{4}$

${ }^{1}$ Médico Ortopedista. Hospital Ipiranga, Brazil

${ }^{2}$ Residente em Ortopedia. Hospital Ipiranga, Brazil

${ }^{3}$ Hospital Do Servidor Publico Municipal De Sao Paulo, Brazil

${ }^{4}$ Unidades Nilton Lins, Brazil

\begin{abstract}
CrossFit is a strength and conditioning program that has gained popularity since its inception approximately 15 years ago. However, little is currently known about the level of injury risk associated with this form of training. The aim of this study was to evaluate the injury incidence rate associated with CrossFit training and to point out the site most affected by the injuries. The search of articles in the databases resulted in 93 files in Portuguese and 476 in English, but only 62 files were selected for analysis, since the others did not address the topic of interest. Of the 62 studies included, 15 articles were performed with samples collected from both sexes. Among 6,169 participants, 2,063 injuries were recorded. Articles were published between 2015 and 2019. Injury prevalence ranged from $12.8 \%$ to $92.5 \%$ between studies. According to the meta-analysis of 15 studies, the prevalence of injuries was 33.4\% (95\% CI 32.2\% -34.6\%). The I2 value of 26.3 revealed low heterogeneity between studies. The prevalence of injuries among male crossfit practitioners was 58.5\%. The prevalence of shoulder injury was predominant in studies with an average equal to $35.2 \%$. It is important to identify the prevalence of musculoskeletal injuries in the Crossfit modality in order to adopt effective preventive measures, since musculoskeletal injuries are among the most common complaints in orthopedic care, which occurs in both athletes and non-athletes. The incidence rate of injuries associated with CrossFit training was low and comparable to other forms of recreational activities. The incidence rate of injuries associated with CrossFit training was low and comparable to other forms of recreational activities. The shoulder was the main joint affected by injuries due to CrossFit training.
\end{abstract}

Keywords: Crossfit, Injuries, Prevalence

\section{Introduction}

CrossFit is recognized as one of the fastest growing modes in high intensity functional training. According to CrossFit's official website (map.crossfit.com), CrossFit gyms are located in 142 countries on seven continents, with more than 10,000 affiliates. This strength and conditioning program is used to optimize physical competence in ten domains of fitness: (1) cardiovascular / respiratory resistance, (2) endurance, (3) strength, (4) flexibility, (5) power, (6) speed, (7) coordination, (8) agility, (9) balance and (10) precision. CrossFit training is usually performed with high intensity functional movements called "workout of the day" (WOD). In these training sessions, high intensity exercises are performed quickly, repetitively and with little or no recovery time between sets. With a focus on functional movements in constant variation, CrossFit training uses the main elements of gymnastics (for example, pin and ring exercises), weightlifting exercises (for example, squats and presses) and cardiovascular activities (for example, running or rowing) as exercise tasks. According to Glassman, who is the founder of CrossFit, the methodology that drives CrossFit training is totally empirical. In addition, Glassman described that "significant statements about safety, effectiveness and efficiency, the three most important and interdependent facets of any fitness program, can be supported only by measurable, observable and repeatable facts, that is, data". ${ }^{1-3}$ CrossFit is also considered an option for high intensity interval training (HIIT). Consequently, HIIT has become

\begin{tabular}{l|l|}
\hline Quick Response Code: & *Corresponding author: José Carlos Figueiredo Fernandes, Médico Ortopedista, Hospital \\
Ipiranga, Brazil \\
Received: 09 April 2021 \\
Citation: Fernandes JCF, Moraes LMRP, Cattaneo LG, Gomes WF, Galotti R. Incidence of \\
CrossFit Related Injuries: A Metaalysis. SOJ Ortho Rehab. 2021;1(1):1-8. DOI: 10.53902/SO- \\
JOR.2021.01.000503
\end{tabular}


one of the top 3 global fitness trends since 2013, according to the American College Sports Medicine (ACSM) annual survey Notably, CrossFit was indicated as the main reason why HIT's training was rated so high. ${ }^{6-9}$ However, a consensus document produced by the Military Health and Performance Consortium (CHAMP) and ACSM associated a potential high risk of injury emergency with programs like CrossFit.

Although positive influences on body composition and physical fitness have been recognized, the consensus highlighted a "disproportionate risk of musculoskeletal injury from these demanding programs, especially for beginning participants, resulting in lost time in service, medical treatment and extensive rehabilitation". In addition, the consensus suggested the existence of a training paradigm that requires advanced level technique during maximum repetitions of timed exercises without adequate rest intervals between sets, as well as an insufficient recovery time between high volume loads and training sessions. This overload situation can lead to early fatigue, additional oxidative stress, less resistance to repetitive efforts after exercise, greater perception of effort and unsafe execution of movements. ${ }^{10}$

In addition, this training context associated with inadequate progression of the training load increases the risk of injuries from overuse. The consensus authors suggested, as a possible solution, the individual monitoring of the training load to minimize these risks. ${ }^{10}$ Despite the proposed risks for CrossFit, others have suggested that high-intensity functional training programs, including CrossFit, have similar or less potential for injuries than many traditional physical training activities. However, the authors also stated that training volume control should be done to reduce the risk of injury to military populations. For an effective training and adapta- tion process to take place, monitoring, quantifying and regulating the training load is necessary. However, managing the training load represents a considerable challenge for sports scientists. Despite this challenge, managing the training load is critical to achieving the goals of reducing the risk of injury and optimizing sports performance. Due to the increase in practitioners of the sport around the world, there is a mutual interest in the practicing community and those interested in the sport, as well as in health professionals, regarding the possible injuries developed during the sport. Although there are a large number of CrossFit supporters, the evidence empirical results that demonstrate the improvements in physical fitness that arise from this form of training are far from substantial. Therefore, the objective of the present study is to analyze the findings of the scientific literature related to the injury incidence rate and the risk factors associated with the practice of CrossFit, through a systematic review and analysis.

\section{Material and Methods}

\section{Search for items}

An author conducted the bibliographic search, gathered the abstracts, and applied the initial inclusion criteria. The keywords "CrossFit", "injuries" and "incidence" were used during the electronic search. The following electronic databases were searched on August 18, 2019: PubMed, Bireme/MedLine and SciELO (Figure 1). The reporting guidelines for preferred reporting items for systematic reviews and meta-analyzes (PRISMA) have been adhered to in this manuscript. In the initial analysis, all CrossFit articles included in this manuscript were peer-reviewed, limited to the period from 2015 to 2018 and in Portuguese and English. During the second phase of the study selection, two authors reviewed and identified the titles and abstracts based on the inclusion criteria.

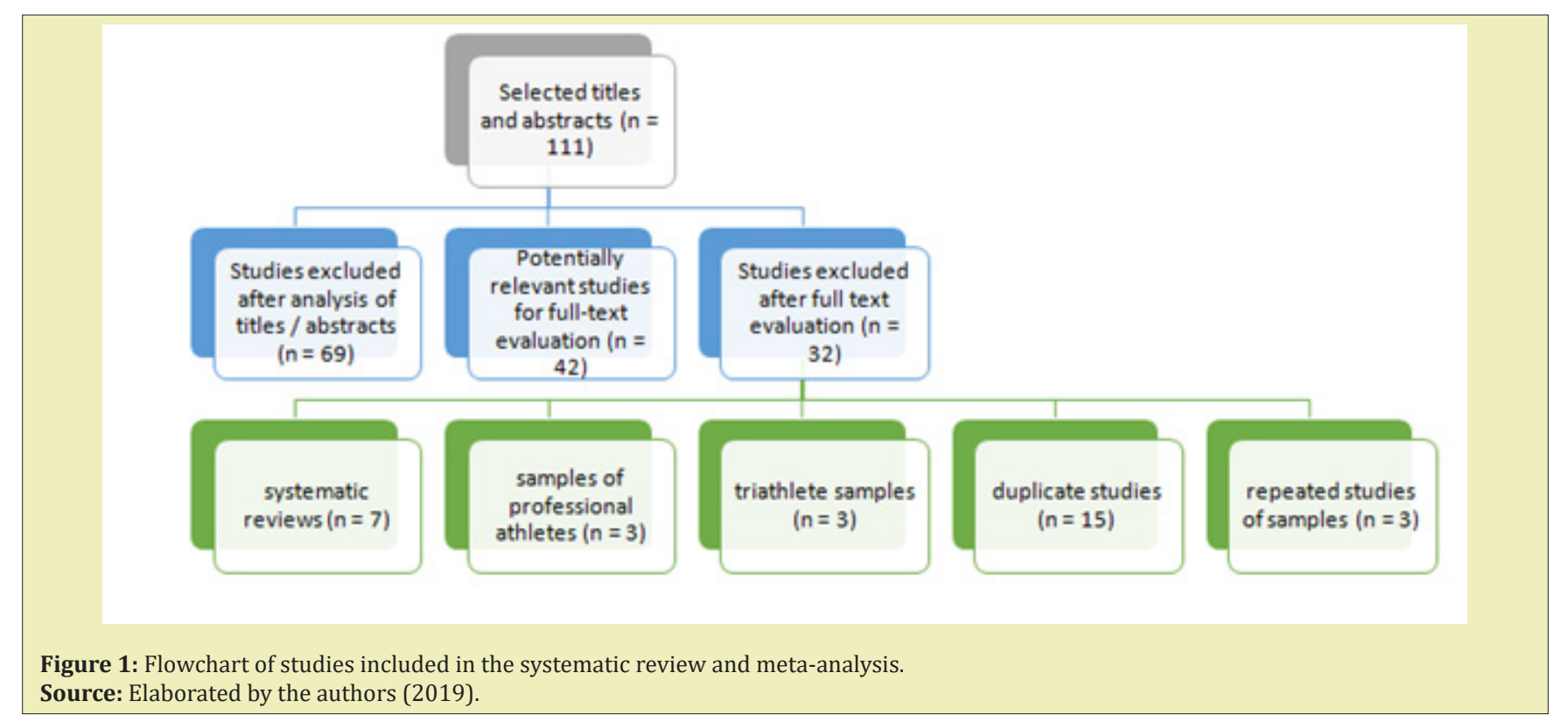




\section{Inclusion criteria}

To meet the inclusion criteria for the meta-analysis, studies that investigated human beings "in vivo" and analyzed the effects of CrossFit as a training program were considered. The meta-analysis was performed only on variables from short-term intervention studies (that is, $\geq 3$ weeks) with healthy male and/or female participants, divided into gender groups (the procedures were consistent with those of another meta-analysis). In addition, the variables analyzed were found in more than one study. If the original data were not provided by the authors, the mean and standard deviations were extracted from the graphical representation using Ycasd or estimated from the median, range, and sample size. Systematic review studies, studies carried out with samples of professional athletes and triathletes, case report articles and reviews and duplicate articles in more than one database were excluded from this investigation. When the same sample was used to report the prevalence of injuries in more than one study, only the study with the largest sample size was included in this research.

\section{Statistical analysis}

The data were initially analyzed using descriptive statistics. The prevalence estimates and their respective confidence intervals (CIs) were obtained from the total sample size of individuals practicing CrossFit and the number of events (injuries) for each study included in the review. Incidence estimates are expressed as percentages (proportion $\times 100$ ). For the meta-analysis, the heterogeneity of the included studies was assessed by examining the forestplots, confidence intervals (CI) and I2 graphs. I2 values of 25, 50 and 75 indicated low, moderate and high heterogeneity, respectively. Random effects were analyzed using the DerSimonian and Laird approach. The meta-analysis was performed based on the number of variables in short-term intervention studies.

Statistical significance was established at $\mathrm{p} \leq 0.05$, and the magnitude of the differences for each dependent variable was calculat- ed using the effect size (TE) with a 95\% CI 27. The TE classification was large $>0.80$; moderate $=0.20-0.80$; small $<0.20$. Subsequently, meta-regression analyzes were performed in order to investigate the relationship between training characteristics (crossfit frequency [weekly], crossfit experience [years]) and the onset of injuries, to verify the effect of sex on prevalence. lesions, assess the anatomical sites most affected (for example, hip, knee and ankle) and check the most frequent types of injuries (muscle, inflammatory, bone and ligament injuries). Some studies claim that CrossFit presents an inherent risk of injury, specifically in the shoulder, due to the intensity of the training. Currently, there is limited evidence to support this claim. In summary, the following variables were extracted from each study included in the review: total sample size, number of events (injuries), training characteristics (crossfit frequency [weekly], crossfit experience [years]) and the start of injuries, to verify the effect of sex on the prevalence of injuries, the most affected anatomical sites and the most frequent types of injuries (muscle, inflammatory, bone and ligament injuries). All data were analyzed using the Review Manager software version 5.3 and the Excel 2016 spreadsheet (Microsoft, Washington, USA).

\section{Results}

The search for articles in the databases resulted in 93 files in Portuguese and 476 in English, however only 62 files were selected for analysis, since the others did not address the topic of interest. Of the 62 studies included, 15 articles were performed with samples collected from both sexes. Among 6,169 participants, 2,063 injuries were registered. The articles were published between 2015 and 2019. Table 1 shows that all studies provided a definition of injury and 13 studies did not provide enough data to extract information about the prevalence of injuries in relation to the participants' sex. The prevalence of injury varied from $12.8 \%$ to $92.5 \%$ between studies. According to the meta-analysis of 15 studies, the prevalence of injuries was $33.4 \%$ (95\% CI 32.2\% -34.6\%). The I2 value of 26.3 revealed low heterogeneity between the studies (Figure 2).

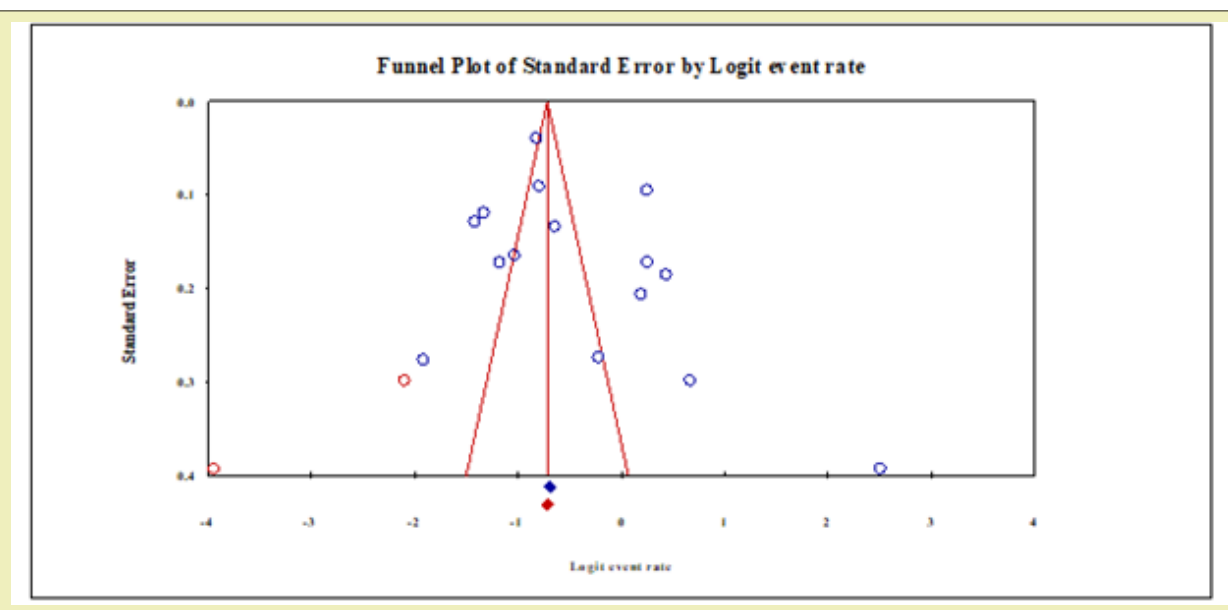

Figure 2: Funnel plot of standard error by event rate $(n=15)$. 
Table 1: Injury incidence rate in crossfit practitioners, by study included in the systematic literature review.

\begin{tabular}{|l|l|l|l|l|l|}
\hline Article & Authors & Year & N & Injuries (n) & Incidence \\
\hline A01 & ${\text { Xavier; } \text { Lopes }^{30}}^{3}$ & 2017 & 137 & 77 & $56.20 \%$ \\
\hline A02 & Mehrab $^{31}$ & 2017 & 449 & 252 & $56.10 \%$ \\
\hline A03 & Montalvo $^{32}$ & 2017 & 191 & 50 & $26.20 \%$ \\
\hline A04 & Sprey $^{33}$ & 2016 & 566 & 176 & $31.10 \%$ \\
\hline A05 & Chachula, Cameron, Svoboda $^{34}$ & 2016 & 54 & 24 & $44.40 \%$ \\
\hline A06 & Lisboa $^{35}$ & 2015 & 95 & 52 & $54.70 \%$ \\
\hline A07 & Weisenthal $^{36}$ & 2015 & 386 & 75 & $19.40 \%$ \\
\hline A08 & Summitt $^{37}$ & 2016 & 187 & 44 & $23.50 \%$ \\
\hline A09 & uune, Power $^{33} 8$ & 2017 & 247 & 85 & $34.40 \%$ \\
\hline A10 & Feito, Burrows, Tabb $^{39}$ & 2018 & 3049 & 931 & $30.50 \%$ \\
\hline A11 & Elkin $^{\text {40 }}$ & 2019 & 122 & 74 & $60.70 \%$ \\
\hline A12 & Hopkins $^{41}$ & 2017 & 426 & 89 & $20.90 \%$ \\
\hline A13 & Soares $^{42}$ & 2016 & 50 & 33 & $66.00 \%$ \\
\hline A14 & Porse, Rodrigue $^{\text {s4 } 3}$ & 2018 & 93 & 86 & $92.50 \%$ \\
\hline A15 & Mora $^{\text {n4 } 4}$ & 2017 & 117 & 15 & $12.80 \%$ \\
\hline
\end{tabular}

Source: Data resulting from the research.

The prevalence of injuries among male crossfit practitioners was $58.5 \%$. The prevalence of shoulder injury was predominant in studies with a mean of $35.2 \%$. One way of avoiding heterogeneous results is to include in the systematic review only methodologically similar studies by performing the heterogeneity test. To identify the heterogeneity in the findings, statistical techniques are applied in order to verify whether the differences observed in the results can be explained or not by chance. The chi-square test is one of the most used to assess the significance of heterogeneity, with a more conservative level of significance of $\mathrm{p}<0.10$, instead of the usual $\mathrm{p}<0.05$. The magnitude of the heterogeneity is ascertained mainly by calculating the I2, which ranges from 0 to $100 \%$. An I 2 greater than $50 \%$ indicates substantial heterogeneity and, above $75 \%$, considerable heterogeneity. The greater the heterogeneity, the greater the question about the validity of combining results. In the pres- ence of heterogeneity, it is recommended to investigate its causes through sensitivity analysis and meta-regression.

The data selected to compose the meta-analysis may be influenced by the publication bias. Publication bias means the tendency for published results to be systematically different from reality. In systematic reviews, the presence of this bias can be identified by means of the funnel graph and statistical tests. The use of these techniques is recommended for meta-analyzes with ten studies or more and is based on questions of estimation and precision. Inaccurate studies, usually performed with small sample sizes, may find positive or negative results (statistically significant or not) due to the influence of chance. They would be distributed symmetrically over the widest part of the funnel. Higher precision studies, generally in smaller numbers, would be closer to the real value and located in the narrowest part of the funnel (Figure 2) (Table 2 \& 3).

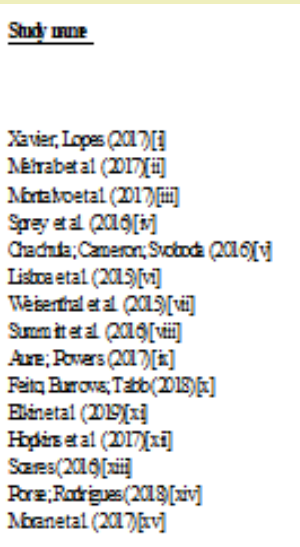

\begin{tabular}{|c|c|c|c|c|c|}
\hline \multicolumn{6}{|c|}{ Statitios fre exhstudy } \\
\hline ent & $\begin{array}{l}\text { Lower } \\
\text { linit }\end{array}$ & $\begin{array}{l}\text { पypr } \\
\text { mit }\end{array}$ & dife & pVahe & 7 \\
\hline & 0.48 & 064 & 49 & 0.147 & $7 \%$ \\
\hline & 0.515 & & & 10 & \\
\hline 226 & 0.204 & 29 & 6299 & 0,000 & \\
\hline 2311 & 0274 & 350 & -876 & 2000 & 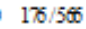 \\
\hline 444 & 0319 & 0578 & -0815 & 0.415 & $24 / 54$ \\
\hline 547 & 0.447 & 0644 & 092 & 0357 & $52 / 96$ \\
\hline 194 & 0.158 & 0287 & -11056 & 0,000 & $75 / 386$ \\
\hline 235 & 0.180 & 0301 & -6857 & 2000 & $44 / 187$ \\
\hline 0344 & 0.288 & 0406 & -4815 & 2000 & $85 / 247$ \\
\hline 305 & 0289 & 202 & -20903 & 2000 & $931 / 3049$ \\
\hline & 0.517 & & & 20 & \\
\hline & 0.173 & 0230 & -11.172 & 0,000 & $89 / 46$ \\
\hline & 0520 & $0 \pi 7$ & 22 & 0,026 & $33 / 50$ \\
\hline & 0.8 & 09 & & 0,000 & $86 / 98$ \\
\hline & 0,079 & 0202 & -6932 & 0,000 & $15 / 117$ \\
\hline & & & & 20 & \\
\hline
\end{tabular}

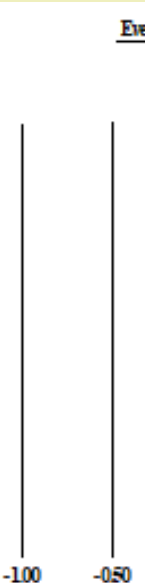

Evert nate ad $9 \$ \%$ व

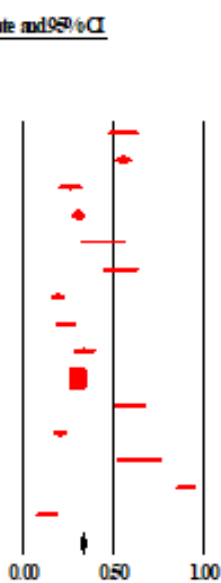

\begin{tabular}{|c|c|c|}
\hline \multicolumn{3}{|c|}{ Weigit (Frived) } \\
\hline $\begin{array}{l}\text { Relative } \\
\text { weight }\end{array}$ & $\begin{array}{l}\text { Reltive } \\
\text { weight }\end{array}$ & $\begin{array}{c}\text { Std } \\
\text { Reiind }\end{array}$ \\
\hline 206 & & 55 \\
\hline 87 & & 1030 \\
\hline 292 & & -214 \\
\hline 9.58 & & -123 \\
\hline 105 & & 17 \\
\hline 186 & & 431 \\
\hline 47 & & -584 \\
\hline 206 & & -287 \\
\hline 440 & & 0.34 \\
\hline 5108 & & -481 \\
\hline 230 & & $6 \mathrm{~B}$ \\
\hline 556 & & -554 \\
\hline 0.9 & & 455 \\
\hline 0.51 & & 8.15 \\
\hline 10 & & -446 \\
\hline
\end{tabular}

Figure 3: Forest Plot of the meta-analysis of the prevalence of injuries and their respective confidence intervals in Crossfit practitioners, by study included in the Systematic Literature Review.

Source: Data resulting from the research. 
Table 2: Injury incidence rate in crossfit practitioners, by study included in the systematic literature review.

\begin{tabular}{|c|c|c|c|c|c|}
\hline \multirow{2}{*}{ Article } & \multirow{2}{*}{$\begin{array}{l}\text { Injury rate } \\
\text { p/ } 1000 \text { hours }\end{array}$} & \multirow{2}{*}{ Middle Ages } & \multirow{2}{*}{ Male } & \multirow{2}{*}{ Feminine } & \multirow{2}{*}{$\begin{array}{l}\text { anatomical sites } \\
\text { most affected }\end{array}$} \\
\hline & & & & & \\
\hline A01 & - & $31,1 \pm 6,1$ & 54 & 23 & Shoulder $(27 ; 35,1 \%)$ \\
\hline A02 & - & $31.9 \pm 8.3$ & 157 & 95 & Shoulder $(87 ; 28,7 \%)$ \\
\hline A03 & 2.3 & $31.42 \pm 8.34$ & 30 & 20 & Shoulder $(14 ; 22,6 \%)$ \\
\hline A04 & - & $31.3 \pm 7$ & 109 & 67 & - \\
\hline A05 & - & - & - & - & - \\
\hline A06 & - & 25.6 & 35 & 17 & Shoulder $(11 ; 44 \%)$ \\
\hline A07 & 2.4 & - & 54 & 21 & Shoulder $(21 ; 28 \%)$ \\
\hline A08 & 1.94 & - & - & - & - \\
\hline A09 & 2.71 & $38.9 \pm 8.9$ & 64 & 21 & Shoulder (38; 50.7\%) \\
\hline A10 & - & - & 495 & 436 & - \\
\hline A11 & - & $32,82 \pm 11,55$ & 40 & 34 & Shoulder $(46,41 \%)$ \\
\hline A12 & - & $37.2 \pm 68.9$ & 51 & 38 & Spine $(20,9 \%)$ \\
\hline A13 & - & $33,9 \pm 7,4$ & 14 & 19 & Shoulder $(10 ; 52,6 \%)$ \\
\hline A14 & - & $31.42 \pm 1.10$ & 55 & 31 & Shoulder $(20 ; 23,3 \%)$ \\
\hline A15 & 2.1 & $35 \pm 10$ & - & - & - \\
\hline Total & & & $1.158(58,5 \%)$ & $822(41,5 \%)$ & $35,2 \%$ \\
\hline
\end{tabular}

Table 3: Approach to heterogeneity in meta-analysis on the prevalence of injuries in crossfit practitioners.

\begin{tabular}{|c|c|c|c|c|c|c|c|c|c|c|}
\hline \multirow{2}{*}{\multicolumn{2}{|c|}{ Model }} & \multirow{2}{*}{\multicolumn{3}{|c|}{$\begin{array}{l}\text { effect size } \\
\text { e IC } 95 \%\end{array}$}} & \multirow{2}{*}{\multicolumn{2}{|c|}{$\begin{array}{l}\text { Test of null } \\
\text { (2-Tail) }\end{array}$}} & \multirow{2}{*}{\multicolumn{4}{|c|}{ Heterogeneity }} \\
\hline & & & & & & & & & & \\
\hline & \multirow{2}{*}{$\mathrm{N}$} & Point & \multirow{2}{*}{ Inferior } & \multirow{2}{*}{ Superior } & \multirow{2}{*}{$\mathrm{Z}$} & \multirow{2}{*}{ P-valor } & \multirow{2}{*}{ Q } & \multirow{2}{*}{$\mathrm{Gl}$} & \multirow{2}{*}{ P-valor } & \multirow{2}{*}{$\mathrm{I}^{2}$} \\
\hline & & Estimated & & & & & & & & \\
\hline Fixed & 15 & 0.334 & 0.322 & 0.346 & -24.54 & 0 & 377.5 & 14 & 0 & $26.30 \%$ \\
\hline Random effects & 15 & 0.404 & 0.326 & 0.487 & -2.27 & 0.023 & & & & \\
\hline
\end{tabular}

Tau2: 0.404; Standard Error: 0.259; variance: 0.067; Tau: 0.635 .

\section{Discussion}

CrossFit is a form of exercise that incorporates high-intensity, rapid and successive ballistic movements. As CrossFit is an increasingly popular fitness option, it is important to determine injury incidence rates among exercise practitioners. This review was carried out to check the incidence of injury with CrossFit in the past five years. Although high-intensity interval exercise is not a new concept, the CrossFit model of combining several high-intensity functional movements is a relatively recent fashion. CrossFit is an exercise program that uses high intensity functional movements with limited amounts of rest to increase strength and endurance using a combination of cardiovascular exercises, weightlifting (Olympic and power) and gymnastics. Given the novelty of CrossFit training, there is currently limited research on injury rates. ${ }^{11-35}$ However, the 15 articles retrieved for this review revealed that the injury rate with CrossFit is comparable to or less than the injury rate with Olympic weightlifting, distance running, military conditioning, athletics, rugby or gymnastics. ${ }^{36-38}$
Each article defines injuries differently, with Weisenthal et al., ${ }^{36}$ describing it as "pain, sensation or musculoskeletal injury as a result of CrossFit training that led to at least one of the following situations: total removal of CrossFit or other physical activity for more than 1 week. $^{39-44} \mathrm{~A}$ comparison of the existing literature helps to understand this high incidence of injuries. A recent study by Sprey et al. ${ }^{4}$ in Brazil found an injury incidence rate of $31.1 \%$ for CrossFit athletes. Previous studies that examined injuries at CrossFit found injury incidence rates of $19.4 \% 36$ and $92.5 \%{ }^{43}$ However, the definition used in these epidemiological studies of "injury" certainly influences the results. We used a strict definition, which was in line with the definition used in the studies by Weisenthal et al., ${ }^{36}$ and Sprey et al. ${ }^{4}$ defined an injury as "any injury suffered during training that prevented the participant from training, working or competing in any way and for any period of time". This broad and nonspecific definition may explain the high incidence rate of injuries of $92.5 \%$ reported in that study.

In addition, in a study investigating only shoulder injuries in 
CrossFit athletes, Summit et al., ${ }^{29}$ found that the incidence of new shoulder injuries was 1.94/1000 hours of training for athletes. This was more than double the reported incidence. However, Summit et al., ${ }^{29}$ specifically targeted CrossFit athletes with shoulder injuries.

The injury rate at CrossFit was lower than that reported by Winwood et al. in strong competitive men (5.5 injuries/1000 hours). This finding is interesting because the results of Montalvo32 suggest that taller and heavier athletes are more likely to suffer injuries. In the study by Winwood et al. reported that the mean height and mass of their strongest respondents were $1.83 \pm 0.07 \mathrm{~m}$ and $113 \pm 20 \mathrm{~kg}$, respectively. Respondents were considerably larger than respondents who reported injury $(1.72 \pm 0.09 \mathrm{~m}, 78.2 \pm 16.9 \mathrm{~kg})$. In addition, Chachula et al., ${ }^{34}$ suggest that it is the nature of the movements that can result in a higher injury rate in strong male athletes.

Although Crossfit incorporates elements of strong men, they may not be the elements that put athletes at the greatest risk of injury. These elements include stones, tire rotation and log press, among others. ${ }^{38}$ Overall, we found that the incidence of injuries in CrossFit athletes was similar to related sports. ${ }^{38}$ Considering the popularity of this training program and the differences found between men and women, as well as between levels of experience, it is important to describe injuries in a way that can be compared across studies. As such, it is important to compare injury rates rather than simply the incidence of injuries, as exposure to training (ie, how often) will have an impact on the likelihood of an injury occurring. Although we have provided participation-based injury estimates, our overall findings are well below the previously reported injury rates. In CrossFit, Weisenthal et al. ${ }^{36}$ observed that female participants were more likely to seek help from a trainer. Thus, female participants may be more likely to use appropriate loads and/or correct movement patterns, which can subsequently reduce the risk of injury compared to men. Related to this, it has been reported that men who participate in CrossFit have higher levels of 'performance approach objectives' compared to women, who are more likely to prioritize the technique domain; 40,44 an emphasis on performance over the domain of technique can also explain the higher injury rate seen in male CrossFit participants.

For example, Aune et al. ${ }^{38}$ reported 247 participants (38.9 \pm 8.9 ) and calculated an injury rate of 2.71 per 1,000 hours. Meanwhile, Weisenthal et al. ${ }^{36}$ reported 486 participants in CrossFit training and reported a $19.4 \%$ injury incidence, without a specified injury rate. However, this injury rate was later reported as 2.4 injuries per 1,000 hours of training. ${ }^{36}$ More recently, Mehrab et al., ${ }^{31}$ surveyed 449 Dutch CrossFit athletes and reported an incidence of $56.1 \%$ injuries and, although did not provide an injury rate, they reported that athletes with less than 6 months of experience had an almost four times higher risk of injuries compared to those with more than 24 months of experience. According to the findings of Chachula et al., ${ }^{34,42}$ CrossFit participants who had suffered a previous injury in the last six months had a substantially higher risk of injury when compared to those who had not suffered a previous injury. The increased risk of injury due to previous injuries has been well documented in sporting environments. ${ }^{33,35}$ and in recreational activities. ${ }^{30}$ The reasons offered to explain the role of the previous injury as a risk factor include imbalance and impaired muscle strength, decreased flexibility, flexibility and functionality or mechanical instability and the presence of scar tissue. ${ }^{45}$ However, it is also possible that a previous injury simply acts as a 'marker' for participants with a higher risk of underlying injury, rather than actually increasing the risk of underlying injury within a given participant. The shoulder was the main joint affected by injuries due to CrossFit training. ${ }^{30-32}$ According to studies, this result is related to the execution of some exercises that have been considered harmful in the practice of Crossfit, as they have a high range of motion of the shoulder complex, a characteristic that can increase the risk of injury, since movements above the shoulder joint line predispose to injuries due to the reduction of the subacromial space.

In addition to exercises derived from gymnastics, the characteristic exercises of Olympic weightlifting that make up CrossFit, such as overhead squat, require the placement of the shoulder joint in positions of extreme flexion, abduction and internal rotation, which increase the risk of injury. ${ }^{40}$ Due to the high incidence of shoulder injuries found in the studies, greater caution is suggested about gymnastic exercises and Olympic weightlifting by practitioners and professionals who supervise the execution of these movements, focusing on factors such as excessive and technical effort inadequate, factors pointed out by athletes as causing injuries in 35 and $20 \%$ of cases, respectively. ${ }^{38}$

\section{Conclusion}

It is important to identify the prevalence of musculoskeletal injuries in the Crossfit modality, so that effective preventive measures can be adopted, because musculoskeletal injuries are among the most common complaints in orthopedic care, which occurs in both athletes and non-athletes. The injury incidence rate associated with CrossFit training was low and comparable to other forms of recreational activities. The shoulder was the main joint affected by injuries due to CrossFit training.

\section{Acknowledgements}

None.

\section{Funding}

None.

\section{Conflicts of Interests}

The authors declare no conflict of interest. 


\section{References}

1. Beers, Emily. Virtuosity goes viral. The CrossFit Journal. 2014;6:1-10.

2. Santos. Isadora Lima dos. Produção científica relacionada ao crossfit no Brasil. Educação Física. 2018.

3. Tibana, Ramires Alsamir, De Almeida, et al. Crossfit® riscos ou benefícios? 0 que sabemos até o momento. Revista Brasileira de Ciência e Movimento. 2015;23(1):182-185.

4. Sprey Jan WC, Thiago Ferreira, Marcos V de Lima, et al. An epidemiological profile of crossfit athletes in Brazil. Orthopaedic journal of sports medicine. 2016;4(8):2325967116663706.

5. Fisker FY, Kildegaard S, Thygesen M, et al. Acute tendon changes in intense CrossFit workout: an observational cohort study. Scandinavian journal of medicine \& science in sports. 2017;27(11):1258-1262.

6. Thompson, Walter R. Worldwide survey of fitness trends for 2019. ACSM's Health \& Fitness Journal. 2018;22(6):10-17.

7. Thompson, Walter R. Worldwide survey of fitness trends for 2018: the CREP edition. ACSM's Health \& Fitness Journal. 2017;21(6):10-19.

8. Thompson, Walter R. Now trending: worldwide survey of fitness trends for 2014. ACSM's Health \& Fitness Journal. 2013;17(6):10-20.

9. Thompson, Walter R. Worldwide survey of fitness trends for 2015: what's driving the market. ACSM's Health \& Fitness Journal. 2014;18(6):8-17.

10. Glassman JA. Consortium for Health and Military Performance and American College of Sports Medicine Consensus Paper on Extreme Conditioning Programs in Military Personnel: An Answer. CrossFit Journal. 2012. p. 1-92.

11. Feito Yuri, Katie M Heinrich, Scotty J Butcher, et al. High intensity functional training (HIFT): Definition and research implications for improved fitness. Sports. 2018;6(3):76.

12. Akenhead Richard, Nassis George P. Training load and player monitoring in high-level football: current practice and perceptions. International journal of sports physiology and performance. 2016;11(5):587593.

13. Borresen Jill, Lambert Michael Ian. The quantification of training load, the training response and the effect on performance. Sports medicine. 2009;39(9):779-795.

14. Siff MC. Super training, 6th editition. Supertraining Institute, 2003; p. 290.

15. Halson Shona L. Monitoring training load to understand fatigue in athletes. Sports medicine. 2014;44(2):139-147.

16. Gabbett T. Infographic: The training-injury prevention paradox: should athletes be training smarter and harder?. British Journal of Sports Medicine. 2018;52(3):203.

17. Amadio Alberto Carlos, Serrão Júlio Cerca. A biomecânica em educação física e esporte. Revista Brasileira de Educação Física e Esporte. 2011;25:15-24.

18. Elliott Bruce. Biomechanics: an integral part of sport science and sport medicine. Journal of Science and Medicine in Sport. 1999;2(4):299310 .

19. Jones Christopher M, Griffiths Peter C, Mellalieu Stephen D. Training load and fatigue marker associations with injury and illness: a systematic review of longitudinal studies. Sports medicine. 2017;47(5):943974.

20. Hopkins William G. Quantification of training in competitive sports. Sports medicine. 1991;12(3):161-183.

21. Claudino João Gustavo. Autoregulating jump performance to induce functional overreaching. Journal of strength and conditioning research. 2016;30(8):2242-2249.
22. Claudino João Gustavo, B Mezêncio, R Soncin, et al. Pre vertical jump performance to regulate the training volume. International journal of sports medicine. 2012;33(2):101-107.

23. Claudino João Gustavo, Tim J Gabbett, Frank Bourgeois, et al. Crossfit overview: systematic review and meta-analysis. Sports medicine-open. 2018;4(1):11.

24. Gross Arnd, Schirm Sibylle, Scholz Markus. Ycasd a tool for capturing and scaling data from graphical representations. BMC bioinformatics. 2014;15(1):219.

25. Hozo Stela Pudar, Djulbegovic Benjamin, Hozo Iztok. Estimating the mean and variance from the median, range, and the size of a sample. BMC medical research methodology. 2005;5(1):13.

26. Higgins Julian PT, Simon G Thompson, Jonathan J Deeks, et al. Measuring inconsistency in meta-analyses. BMJ. 2003;327(7414):557-560.

27. Dersimonian Rebecca, Laird Nan. Meta-analysis in clinical trials. Controlled clinical trials. 1986;7(3):177-188.

28. Cohen Jacob. Statistical power analysis for the behavioral sciences. Routledge. 2013.

29. Summitt Ryan J, Ryan A Cotton, Adam C Kays, et al. Shoulder injuries in individuals who participate in CrossFit training. Sports health. 2016;8(6):541-546.

30. Xavier Alan de Almeida, Lopes Aírton Martins da Costa. Lesões musculoesqueléticas em praticantes de crossfit. Revista Interdisciplinar Ciências Médicas. 2017;1(1):11-27.

31. Mehrab Mirwais, Robert-Jan de Vos, Gerald A Kraan, et al. Injury incidence and patterns among Dutch CrossFit athletes. Orthopaedic journal of sports medicine. 2017;5(12):2325967117745263.

32. Montalvo Alicia M, Hilary Shaefer, Belinda Rodriguez, et al. Retrospective injury epidemiology and risk factors for injury in CrossFit. Journal of sports science \& medicine. 2017;16(1):53.

33. Sprey Jan WC, Thiago Ferreira, Marcos V de Lima, et al. An epidemiological profile of crossfit athletes in Brazil. Orthopaedic journal of sports medicine. 2016;4(8):2325967116663706.

34. Chachula Laura A, Cameron Kenneth L, Svoboda Steven J. Association of prior injury with the report of new injuries sustained during CrossFit training. Athletic Training and Sports Health Care. 2016;8(1):2834

35. Lisboa Alisson Rodrigues, Anderson JS Oliveira, Lucas Resende, et al. Prevalência de lesões em atletas competidores de crossfit. 2015.

36. Weisenthal Benjamin M, Christopher A Beck, Michael D Maloney, et al. Injury rate and patterns among CrossFit athletes. Orthopaedic journal of sports medicine. 2014;2(4):2325967114531177.

37. Summitt Ryan J, Ryan A Cotton, Adam C Kays, et al. Shoulder injuries in individuals who participate in CrossFit training. Sports health. 2016;8(6):541-546.

38. Aune Kyle T, Powers Joseph M. Injuries in an extreme conditioning program. Sports health. 2017;9(1):52-58.

39. Feito Yuri, Burrows Evanette K, Tabb Loni Philip. A 4-Year Analysis of the Incidence of Injuries Among CrossFit-Trained Participants. Orthopaedic Journal of Sports Medicine. 2018;6(10):2325967118803100.

40. Elkin Joshua L, Jacob S Kammerman, Allen R Kunselman, et al. Likelihood of Injury and Medical Care Between CrossFit and Traditional Weightlifting Participants. Orthopaedic journal of sports medicine, 2019;7(5):2325967119843348.

41. Hopkins Benjamin S. Impact of CrossFit-related spinal injuries. Spine. 2017;89:20.

42. Soares Cristina Manuela da Rocha. Prevalência de lesões musculo-esqueléticas em praticantes de instrumentos de sopro ou percussão. Trabalho de Conclusão de Curso. 2016. 
43. Porse Danilo Padilha, Rodrigues Bruno dos Santos. Principais lesões musculoesqueléticas em praticantes de crossfit $®$ da região central do município de Curitiba/PR. 2018.
44. Moran Sebastian, Harry Booker, Jacob Staines, et al. Rates and risk factors of injury in CrossFit: a prospective cohort study. J Sports Med Phys Fitness. 2017;57(9): 1147-1153. 